\title{
Epidemiological Investigation of an Outbreak of Enteric
}

\section{Fever}

\author{
Col A Banerjee (Retd) ${ }^{*}$, Col AT Kalghatgi ${ }^{+}$, Lt Col PMP Singh", Brig A Nagendra (Retd) ${ }^{* *}$, \\ Brig Z Singh (Retd) ${ }^{++}$, Brig SK Handa"\#
}

\begin{abstract}
Background: Ninety five cases of enteric fever among military recruits from a regimental training centre at Maharastra were admitted to the local military hospital in a few weeks time.

Methods: A descriptive epidemiological study and detailed site survey was undertaken. Blood culture, antibiotic sensitivity test (ABST) with serotyping and phage typing of the isolates were done.

Result: A total of 95 cases occurred from 31 March 2003 to 17 May 2003. Blood culture for Salmonella enterica serovar Typhi was positive in $60(63.16 \%)$ cases. All the isolates showed same serotype - 9, 12: d: Vi and all belonged to phage type E1 biotype 1 indicating single source outbreak. There was one fatality. There was clustering in time and place indicating a common source outbreak. Exploration of water pipeline supply revealed sewage contamination due to pipeline passing close to a overflowing manhole. ABST revealed multi-drug resistance.

Conclusion: The outbreak of enteric fever occurred due to sewage contamination of drinking water pipeline.
\end{abstract}

MJAFI 2007; 63 : 322-324

Key Words : Enteric fever; Military recruits

\section{Introduction}

T here has been a steady increase in the incidence of enteric fever in the Indian Armed Forces. In Army it has risen from a rate of 0.13 per 1000 in 1989 to 0.78 per 1000 in 1999; in the Navy from 0.15 per 1000 to 0.80 per 1000 and in the Air Force from 0.07 to 0.52 during the same period [1].

In March-May 2003, an increasing number of fever cases among military recruits from a regimental training centre at Maharastra were admitted to the local military hospital. Epidemic Investigation Team from Armed Forces Medical College assisted in investigation and control of the outbreak. Investigations revealed the cause to be an enteric fever outbreak due to sewage contamination of water pipeline of a particular barrack. This paper describes the details of the outbreak.

\section{Material and Methods}

The study team reviewed all the cases admitted to the local military hospital. A detailed clinical and epidemiological history was taken.

The clinical case definition of typhoid fever was stepladder pattern of fever, headache, rose spots on the trunk, malaise with loss of appetite usually with gastrointestinal symptoms of more than one week duration and having two or more of the following symptoms/signs; toxic look,relative bradycardia, splenic enlargement or non productive cough [2-4].

A case that met the above criteria was taken as suspect case. A probable case was taken as a case compatible with clinical description and either having Widal test titre $\geq 1: 80$ or exposure to a confirmed case/carrier/staying in the incriminated barrack during the last three weeks. A confirmed case was a suspected/probable case that was confirmed by positive blood culture for $S$ typhi. Time, place and person distribution of the cases was worked out. A detailed site survey was conducted.

Blood and serum samples were collected from all the cases for haemogram, blood cultures and Widal test. The antibiotic sensitivity test by disc diffusion method and Minimum Inhibitory Concentration (MIC) was carried out. Presumptive coliform test was conducted on the water samples from the affected barrack and unaffected barracks as controls. Two samples from the affected barrack were taken on $16^{\text {th }}$ April 2003 along with two samples each from adjacent barracks (total 6 samples). Repeat samples from the same sites were collected again on $25^{\text {th }}$ April 2003 after repair of pipelines. The isolates of $S$ typhi obtained on blood culture were sent to Central Research Institute (CRI), Kasauli for serotyping and to Salmonella Reference Centre, Lady Harding Medical College (LHMC), New Delhi for phage typing.

\footnotetext{
*Professor (Community Medicine), Padm Dr DY Patil Medical College, Pune. ${ }^{+}$Ex-Senior Advisor (Pathology), Command Hospital (Central Command) Lucknow. "DADH, Headquarter 21 Mountain Div (Med), C/o 99 APO. **Ex-Dy Commandant, Command Hospital, Chandimandir. ${ }^{++}$Ex-Commandant, Military Hospital Jallandhar. "\#DDMS, Headquarter MB Area (Med), Jabalpur Cantt.
} 


\section{Results}

A total of 95 cases meeting the case definition criteria were admitted. Out of these 60 (63.16\%) were confirmed by blood culture, and the remaining were probable cases.

At the time of admission most of the recruits presented with moderate to high grade fever (mean temperature $101.8^{\circ} \mathrm{F}$ ), some had relative bradycardia, $48 \%$ had pain abdomen, $63 \%$ loose motions, $63 \%$ headache and $57 \%$ cough. Rose spots were detected in less than $20 \%$ of recruits.

The first case reported on 31 Mar 2003, followed by a sudden increase in number of cases. The weekly epidemic curve is depicted in Fig. 1. The median incubation period was about two weeks. The epidemic curve shows a sudden peak and abrupt fall suggestive of common point source outbreak. The curve is not suggestive of person-to-person spread.

Place distribution of typhoid cases is shown in Table 1. 2/1 Training (Trg) Regiment contributed 88 (92.63\%) of the cases. All the cases were from P-9 barrack. This spatial clustering together with temporal clustering was suggestive of common source outbreak. A few sporadic cases occurred in other regiments. Both the cases in 1/1 Trg Regiment which was just adjacent to 2/1 Regt were confirmed cases by blood culture. Out of the three cases in 3/1 Regt, one was confirmed by culture, whereas none of the case in 5/3 Regt and 14/2 Regt were confirmed by culture. These few cases from adjacent training regiments were due to occasional visit of these recruits to $2 / 1$ training regiment for drinking water. The location of the affected P-9 barrack, with the pipeline leak adjacent to overflowing manholes is shown in Fig.2.

All the cases occurred among young recruits within age group of 17-21 years with less than 42 weeks of service. The attack rate for recruits dependent on 2 Bty cook house was

Table 1

Regiment wise distribution of cases

$\begin{array}{lcc}\text { Unit } & \text { Number of cases(\%) } \\ \text { 2/1 Trg Regt } & 88 & (92.64) \\ 3 / 1 \text { Trg Regt } & 03 & (3.16) \\ 1 / 1 \text { Trg Regt } & 02 & (2.10) \\ 5 / 3 \text { Trg Regt } & 01 & (1.05) \\ 14 / 2 \text { Trg Regt } & 01 & (1.05) \\ \text { Total } & 95 & (100)\end{array}$

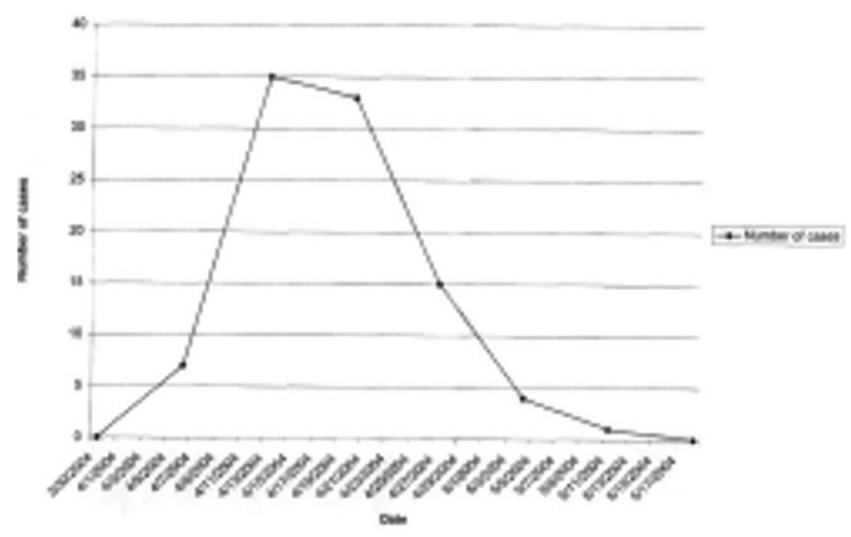

Fig. 1 : Epidemic curve
$12.57 \%$ as compared to almost nil for the rest of the training centre. None of the affected gave history of movement in the past one month outside unit line ruling out outside exposure and none had received typhoid vaccination.

Spatial and temporal clustering of cases was siuggestive of common source outbreak. Sewage pipeline was blocked and manholes were overflowing close to 2 Bty cook house (Fig. 2). On 21 April 2003 exploration by digging along the path of the water pipeline going to this cookhouse was undertaken which revealed massive leakage of water close to overflowing manholes. The water pipeline was totally corroded and leaking. The outbreak was promptly controlled after detection of this pipeline and provision of alternative source of water supply to 2/1 Training Regiment.

On laboratory investigation (Table 2), the haemogram did not reveal any leucopenia or relative lymphocytosis. The mean total leucocyte count was $8383 /$ cumm and mean lymphocyte count was $30 \%$. In 60 of the suspect/probable cases the organism was confirmed as S enterica serovar Typhi (S typhi) on blood culture. Widal test was positive in $77(81.05 \%)$ cases. The antibiotic sensitivity test showed multidrug resistant strains of $S$ enterica serovar Typhi. All the isolates showed a similar antibiogram. The resistance was seen against chloramphenicol, ampicillin and cotrimoxazole. Though the patients did not show good clinical response to ciprofloxacin, the disc diffusion and MIC tests showed the organisms to be sensitive to the drug in vitro (MIC $<1 \mathrm{mcg}$ / $\mathrm{ml}$ ). The isolates were also found to be sensitive to ceftazidime (MIC $<2 \mathrm{mcg} / \mathrm{ml}$ ), which was being exhibited to all the patients and showed the best clinical response. All the isolates showed high degree of resistance to chloramphenicol (MIC $>128$ $\mathrm{mcg} / \mathrm{ml}$ ), ampicillin (MIC > $128 \mathrm{mcg} / \mathrm{ml}$ ), trimethoprim $(\mathrm{MIC}>$ $32 \mathrm{mcg} / \mathrm{ml}$ ) and sulphamethoxazole (MIC $>128 \mathrm{mcg} / \mathrm{ml}$ ).

Serotyping done at CRI Kasauli showed that all the isolates were of the same serotype 9,12:d:Vi. Phage typing done at LHMC, New Delhi, showed that they belong to the same

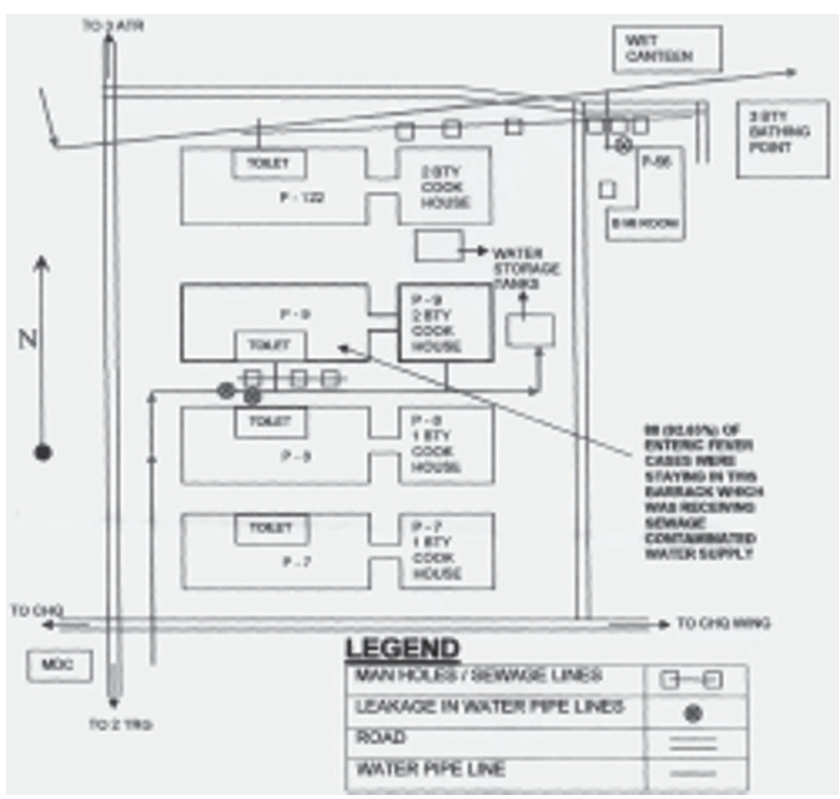

Fig. 2: Spot map number 2 Bty cook house showing sewage contamination of drinking water 
Table 2

Laboratory investigations

$\begin{array}{ll}\text { Test } & \text { Result } \\ \text { Widal test } & \text { Positive in 77(81.1\%) } \\ \text { Blood culture } & \text { Positive for } S \text { enterica serovar Typhi in } 60 \\ & (63.16 \%) \\ \text { Mean TLC } & 8383 / \text { cumm } \\ \text { Mean lymphocyte\% } & 30 \% \\ \text { ABST } & \text { Resistant to: } \\ & \text { (a) chloramphenicol }(\mathrm{MIC}>128 \mathrm{mcg} / \mathrm{ml}) \\ & \text { (b) ampicillin (MIC }>128 \mathrm{mcg} / \mathrm{ml}) \\ & \text { (c) trimethoprim (MIC }>32 \mathrm{mcg} / \mathrm{ml}) \\ & \text { (d) sulphamethoxazole }(\mathrm{MIC}>128 \mathrm{mcg} / \mathrm{ml}) \\ & \text { Sensitive to : } \\ & \text { (a) ciprofloxacin (MIC }<1 \mathrm{mcg} / \mathrm{ml}) \\ & \text { (b) ceftazidine (MIC }<2 \mathrm{mcg} / \mathrm{ml}) \\ \text { Sero typing } & 9,12: \text { d : Vi (all isolates) } \\ \text { Phage typing } & \text { E 1 biotype 1 (all isolates) }\end{array}$

phage type E1 biotype 1 indicating a single source outbreak.

The presumptive coliform tests on both the water samples from 2/1 battery cookhouse on $16^{\text {th }}$ April 2003 were found to be unsatisfactory with coliform counts $>180 / \mathrm{ml}$. Water samples from the adjacent two batteries were satisfactory on $16^{\text {th }}$ April 2003. After repair of pipeline, none of the water samples taken on $25^{\text {th }}$ April 2003 showed any coliforms.

\section{Discussion}

Typhoid fever remains a public health problem in developing countries [5]. Since 1990, outbreaks of enteric fever have been reported from different parts of India [6-8]. Focal common source outbreak of typhoid fever was reported from the campus of the All India Institute of Medical Sciences (AIIMS) in May 2000 [9]. In this outbreak, out of the 26 cases in which the laboratory results were available 11 were culture positive and another nine had high Widal titre. All the $S$ typhi isolates were resistant to chloramphenicol. Grizhebovskii et al [10], reported a focal outbreak of typhoid fever in the Chechen Republic in the year 2000, where drinking water was contaminated from irrigation ditches.

The present outbreak was a common source focal outbreak due to sewage contamination of drinking water to a particular barrack in the regimental centre. In a regimental centre, with a large number of recruits, an occasional carrier can cause an explosive focal outbreak due to sewage contamination of water supply. On occurrence of the outbreak prompt action was taken to check the outbreak. Alternate water supply was established for $2 / 1$ battery. Health education of all recruits for early detection of suspected cases and improvement in personal hygiene was carried out. These measures were successful in checking the outbreak.
Most recent outbreaks of typhoid fever have been due to multidrug resistant strains $[6-8,11,12]$ and prevention is of paramount importance. The problem is compounded by the fact that in most old cantonments, the water and sewage pipelines are very old and their renovation should be given priority. Medical officers should daily monitor the presence of free chlorine in water at all consumer ends, the absence of which should arouse suspicion of sewage contamination of water supply enroute unless proved otherwise.

The increasing number of enteric fever cases in the armed forces may also be due to poor availability of typhoid vaccine (TA) for some time. In view of this TA vaccine has been reintroduced for troops.

\section{Conflicts of Interest}

None identified

\section{References}

1. DGAFMS. Review of Military Hygiene and Health. Manual of Health for the Armed Forces. Directorate General of Armed Forces Medical Services, Min of Defence, New Delhi, Jan 2002: 1-17.

2. National Institute of Communicable Diseases. Standard Case Definitions for epidemic prone diseases; CD Alert 2001; 5(3): $1-8$.

3. National Institute of Communicable Diseases. Investigation and Control of Water Borne Diseases. Directorate General of Health Services, 22 Shamnath Marg, New Delhi, 1998: 1-33.

4. National Institute of Communicable Diseases. Outbreaks: Investigation and Control. Directorate General of Health Services, 22 Shamnath Marg, New Delhi, 1998: 1-44.

5. Saha M R, Dutta P, Palit A, et al. A note on Incidence of typhoid fever in diverse age groups in Kolkata, India. Jour Infect Dis 2003; 56: 121-2.

6. Anand AC, Kataria VK, Singh W, Chatterjee SK. Epidemic multi-resistant enteric fever in eastern India. Letter to the editor. Lancet 1990; 335: 352.

7. Jesudasan MV, John TJ. Multi-resistant Salmonella typhi in India. Letter to the editor. Lancet 1990; 336; 252.

8. Saha MR, Dutta P, Bhattacharya SK, Rasaily R, Mitra U, Dutta D, et al. Occurrence of multi-drug resistant Salmonella typhi in Calcutta. Indian J Med Res 1992; 95: 79-180.

9. National Institute of Communicable Diseases. Outbreaks of water borne diseases. CD Alert 2001;5 (2):1-8.

10. Grizhebovskii G M, Onishchenko GG, Taran VI, et al. Outbreak of typhoid fever in the Chechen Republic in 2000: epidemiological characterization. Zh Mikrobiol Epidemiol Immunobiol 2001, (6 Supplement): 45S-47S.

11. Rathish KC, Chandrashekar MR, Nagesha CN. An outbreak of multidrug resistant typhoid fever in Bangalore. Indian J Pediatrics 1995; 62: 445-8.

12. Swaddiwudhipong W, Kanlayanaphotporn J. A common source water borne outbreak of multidrug resistant typhoid fever in a rural Thai community. J Med Assoc Thai 2001; 84: 1513-7. 